BERKALA FISIKA INDONESIA

\title{
Mengukur cepat rambat bunyi di udara menggunakan sound card stereo dengan metode time of flight
}

\author{
Widi Arief Sandria ${ }^{1 *}$, Ishafit ${ }^{2}$, Fatma Hamid ${ }^{3}$ \\ 1,2 Pendidikan Fisika, Fakultas Keguruan dan Ilmu Pendidikan, Universitas Ahmad Dahlan, Indonesia \\ 3 Pendidikan Fisika, Fakultas Keguruan dan IImu Pendidikan, Universitas Khairun, Indonesia \\ Email: widi1600007027@webmail.uad.ac.id* \\ * Penulis korespondensi
}

\begin{tabular}{l}
\hline Informasi artikel \\
\hline Sejarah artikel: \\
Dikirim \\
Revisi \\
Diterima \\
\hline
\end{tabular}

\section{Kata kunci:}

Cepat rambat bunyi

Metode time of flight

\begin{abstract}
ABSTRAK
Salah satu topik yang menarik untuk diamati dan dilakukan eksperimen di dalam pembelajaran fisika adalah bunyi. Penelitian ini bertujuan untuk mengukur cepat rambat bunyi di udara. Pengukuran cepat rambat bunyi menggunakan sound card stereo dengan metode Time of Flight (ToF). Metode ini memanfaatkan selisih waktu yang ditangkap oleh mikrofon yang berbeda. Dalam penelitian ini, alat ukur yang digunakan yaitu dua buah mikrofon dan software pengolah audio Audacity. Hasil penelitian menunjukkan cepat rambat bunyi di udara sebesar $354 \pm 5 \mathrm{~m} / \mathrm{s}$. Hasil yang diperoleh mendekati dengan nilai eksperimen sebelumnya. Jadi, metode ini terbukti dapat mengukur cepat rambat bunyi di udara dengan cukup akurat dan efektif dengan alat eksperimen yang cukup simpel dan mudah.
\end{abstract}

This is an open access article under the CC-BY-SA license

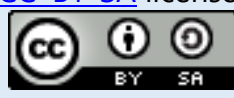

\section{ABSTRACT}

Measuring the rapid propagation of sound in the air using a stereo sound card using the time of flight method. One of the exciting topics to observe and conduct experiments in physics learning is sound. This study aims to measure the speed of sound propagation in the air. Measurement of fast sound propagation using a stereo sound card using the Time of Flight (ToF) method. This method makes use of the time difference captured by different microphones. In this experiment, the measuring instruments used were two microphones and Audacity audio processing software. The results showed that the sound propagation speed in the air was $354 \pm 5 \mathrm{~m} / \mathrm{s}$. The results obtained are close to the previous experimental value. This method is proven to measure the speed of sound propagation in the air quite accurately and effectively with a relatively simple and easy practical tool.

\section{How to Cite:}

Sandria, W. A., Ishafit, \& Hamid, F. (2020). Mengukur cepat rambat bunyi diudara menggunakan sound card stereo dengan metode time of flight. Berkala Fisika Indonesia: Jurnal Ilmiah Fisika, Pembelajaran dan Aplikasinya, 11(2), 40-44. 


\section{Pendahuluan}

Suara adalah salah satu topik yang penting dan menarik untuk diteliti karena berkaitan langsung dengan kompresibilitas zat cair (Yebra et al., 2017). Gelombang suara adalah gelombang longitudinal yang muncul sebagai akibat dari perapatan dan peregangan media gas. (Astuti, 2016; Firdiani, Handhika, \& Kurniadi, 2019; Nasution, Wahab, \& Nuari, 2018). Gelombang bunyi diproduksi ketika ada suatu benda yang bergetar sehingga mengakibatkan adanya perubahan kerapatan medium. Perubahan ini menimbulkan cepat rambat bunyi pada medium gas (Walker et al., 2014). Getaran sebenarnya yang mempengaruhi telinga, gelombang longitudinal, sering disebut sebagai bunyi (Abdullah, 2017; Giancoli, 2015; Monpezat, Topin, Deliere, Farrusseng, \& Coasne, 2019).

Syarat terjadinya bunyi ada tiga yaitu pertama, terdapat sebuah sumber bunyi yang menghasilkan getaran/gelombang bunyi. Kedua, terdapat medium untuk menghantarkan bunyi. Ketiga, terdapat penerima bunyi berupa telinga manusia atau mikrofon (Hartanto \& Haryanti, 2018; Lubis \& Lizalidiawati, 2005). Laju bunyi berbeda untuk materi yang berbeda. Laju bunyi juga bergantung pada temperatur dan tekanan (Boimau, Irmawanto, \& Taneo, 2019; Giancoli, 2015; Ulinuha, 2018). Pada kondisi udara $0^{\circ} \mathrm{C}$ dan tekanan 1 atm, bunyi memiliki kelajuan sebesar $330 \mathrm{~m} / \mathrm{s}$, dan bisa mencapai $344 \mathrm{~m} / \mathrm{s}$ pada suhu udara $20^{\circ} \mathrm{C}$ (Ikhwan \& Pramudya, 2018). Dalam medium padat, bunyi merambat lebih cepat daripada medium cair. Berbagai metode telah dikembangkan untuk mengukur kelajuan bunyi. Misalnya, metode Time of Flight (ToF) berbantuan Audacity (Astuti, 2016), sensor ultrasonik berbasis arduino (Boimau et al., 2019), sistem akuisisi data berbasis smartphone android (Muhafid \& Primadi, 2014), tranduser ultrasonik berbasis mikrokontroler ATMega8535 (Nurkholis, Junaidi, \& Surtono, 2014).

Metode ToF merupakan salah satu metode sederhana untuk pengukuran cepat rambat bunyi karena relative mudah untuk menganalisis data yang diperoleh dan mudah dikembangkan. Pendekatan Time of Flight dapat digunakan untuk menghitung kecepatan propagasi suara di udara. Ketika penerima harus menerima sinyal radio dari pemancar, itu disebut sebagai Time of Flight (ToF) (Astuti, 2016). Oleh karena itu, tujuan penelitian ini yaitu untuk mengukur cepat rambat bunyi di udara menggunakan sound card stereo dengan metode time of flight.

\section{Metode}

Penentuan kelajuan rambat bunyi menggunakan metode Time of Flight (ToF) yaitu mengukur selisih waktu yang ditangkap oleh sensor yang berbeda. Dalam penelitian ini, alat ukur yang digunakan yaitu dua buah mikrofon dan software pengolah audio Audacity. Mikrofon diletakkan terpisah dengan jarak $d$. Kemudian kedua kabel mikrofon digabungkan menjadi satu pada jalur suara kanan dan suara kiri (Gambar 1) sehingga kedua mikrofon dapat dikoneksikan ke komputer dalam mode stereo untuk kemudian dilakukan perekaman suara. 


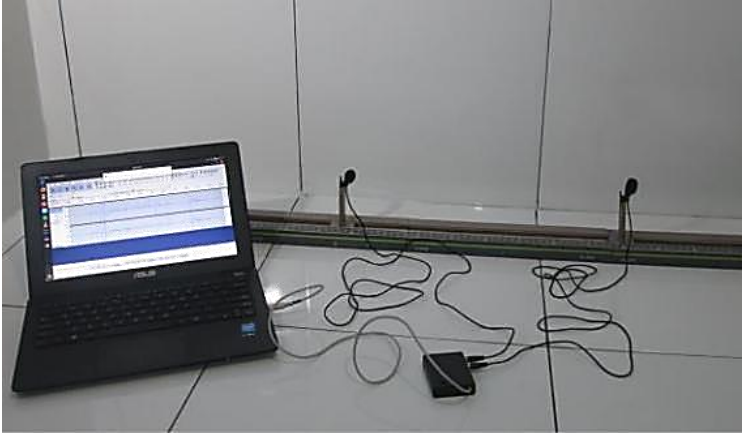

a. Aparatus pengukuran kecepatan bunyi

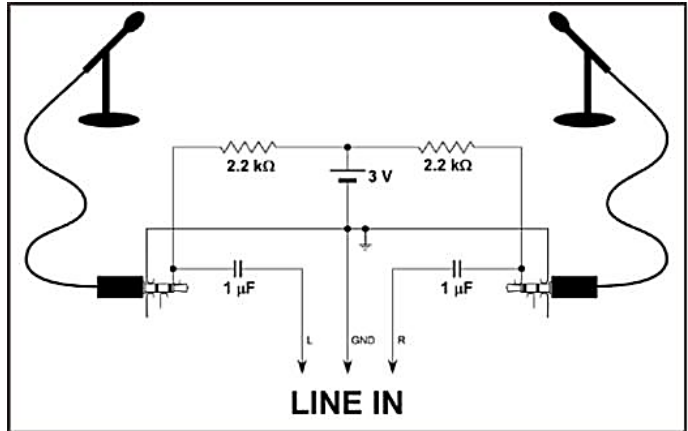

b. Skema alat eksperimen

Gambar 1. Rangkaian alat pengukuran kecepatan rambat bunyi

Prosedur pengambilan data dilakukan dengan cara mengkoneksikan kabel mikrofon yang telah dibuat menjadi stereo ke komputer (Gambar 1) lalu membuka software Audacity kemudian dipilih dalam mode recording. Kemudian membunyikan sebuah bunyi di belakang salah satu mikrofon, sumber bunyi dapat berupa garpu tala atau cukup dengan menepuk tangan. Sumber bunyi harus berupa sumber yang tidak kontinyu. Suara yang terekam oleh audacity dalam dua saluran. Terdapat selisih waktu antara mikrofon satu dan mikrofon dua (Gambar 2) karena mikrofon terpisah pada jarak $d$. Selisih waktu ini yang akan digunakan dalam perhitungan untuk memperoleh cepat rambat bunyi di udara dengan menggunakan persamaan $c_{\text {sound }}=d / t$. Karena selisih waktu yang diukur relatif kecil maka data yang diambil pada Audacity berupa sampel dan kemudian untuk memperoleh waktu sampel dibagi dengan sample rate perekaman yaitu $48000 \mathrm{~Hz}$. Gambar 2 merupakan contoh selisih waktu luaran dari Audacity. Cepat rambat bunyi diperoleh dari kemiringan grafik hasil regresi linear antara selisih waktu dan jarak mikrofon. Ralat pengukuran menggunakan metode perambatan ralat.

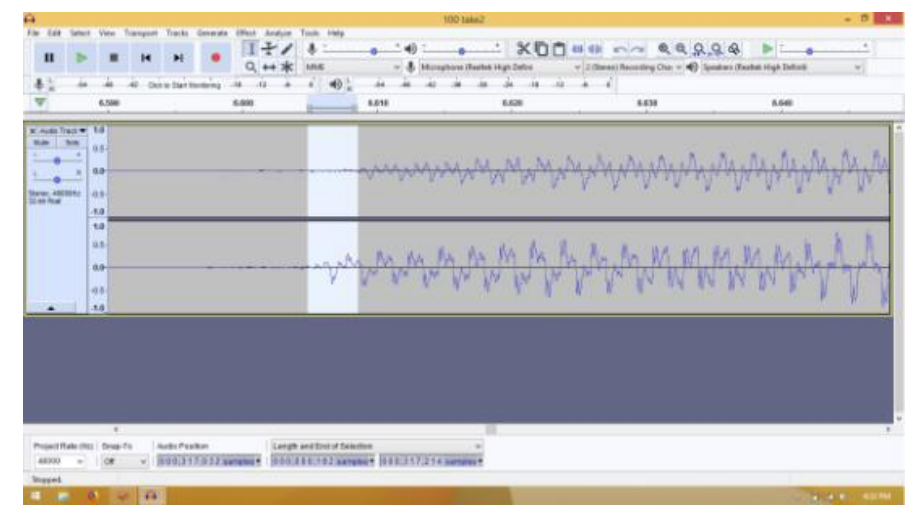

Gambar 2. Selisih waktu suara terdeteksi oleh mikrofon satu dan dua dalam software Audacity

\section{Hasil dan Pembahasan}

Dalam eksperimen ini dilakukan satu kali pengambilan data pengukuran cepat rambat bunyi. Hasil pengukuran yang diperoleh ditampilkan dalam Tabel 1. Kemudian dilakukan plot data pada grafik dengan $d$ sebagai fungsi waktu $t$ sehingga diperoleh hasil cepat rambat bunyi seperti pada Gambar 3 . 
Tabel 1. Data hasil eksperimen

\begin{tabular}{ccc}
\hline Jarak $\boldsymbol{d}(\mathbf{m})$ & Jumlah Sampel & Waktu $\boldsymbol{t}(\mathbf{s})$ \\
\hline 1 & 136 & 0,00283333 \\
0,8 & 106 & 0,00220833 \\
0,6 & 81 & 0,00168750 \\
0,4 & 53 & 0,00110417 \\
0,2 & 27 & 0,00056250 \\
\hline
\end{tabular}

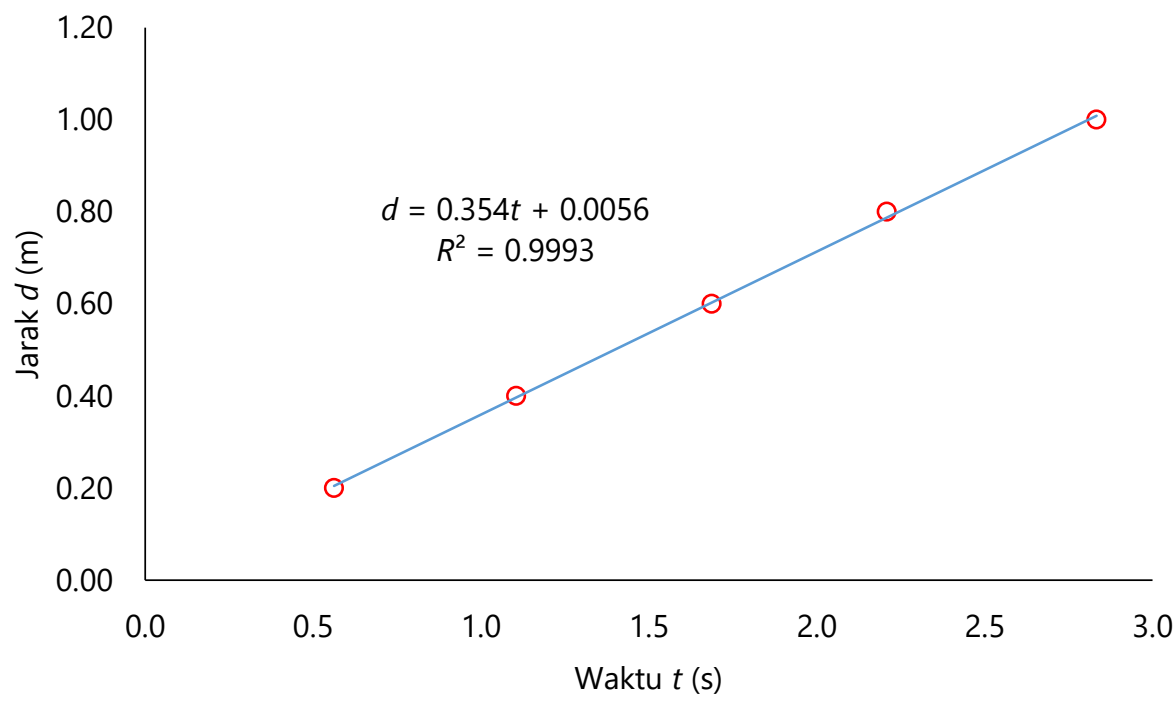

Gambar 3. Grafik hasil pengukuran cepat rambat bunyi

Pada Gambar 3 dapat diketahui nilai gradien garis yang diperoleh yaitu $a=354 \mathrm{~m} / \mathrm{s}$ yang merupakan nilai cepat rambat bunyi. Perambatan ralat yang diperoleh $S_{a}=5,38 \mathrm{~m} / \mathrm{s}$. Jadi nilai cepat rambat bunyi yang diperoleh dari percobaan ini adalah $c_{\text {sound }}=(354 \pm 5) \mathrm{m} / \mathrm{s}$. Nilai ini mendekati nilai hasil pengukuran cepat rambat bunyi pada berbagai penelitian sebelumnya (Astuti, 2016; Boimau et al., 2019; Muhafid \& Primadi, 2014; Nurkholis et al., 2014). Namun hasil yang lebih akurat dapat diperoleh dengan memberikan variasi pada jarak antara mikrofon $d$.

\section{Simpulan}

Pada penelitian ini dapat diambil kesimpulan bahwa cepat rambat bunyi di udara adalah $C_{\text {sound }}$ $=354 \pm 5 \mathrm{~m} / \mathrm{s}$. Hasil ini tidak berbeda jauh dengan hasil pengukuran cepat rambat bunyi di udara pada suhu ruangan yang sudah ada. Metode ini terbukti dapat mengukur cepat rambat bunyi di udara dengan cukup akurat dan efektif dengan alat eksperimen yang cukup simpel dan mudah untuk didemonstrasikan.

Pada eksperimen yang telah dilakukan menggunakan metode TOF, jarak kedua mikrofon tidak dianjurkan untuk terlalu jauh atau terlalu dekat. Jarak mikrofon yang terlalu jauh dapat membuat sumber suara tidak terdeteksi oleh mikrofon yang jauh dari sumber bunyi. Sedangkan jarak yang terlalu dekat membuat selisih waktu bunyi untuk diterima kedua mikrofon sangat kecil sehingga diperlukan 
mikrofon dan alat perekam yang memiliki laju perekaman yang tinggi untuk dapat mendeteksi selisih yang sangat kecil karena hal ini akan mempengaruhi tingkat keakuratan pengukuran.

\section{References}

Abdullah, M. (2017). Fisika dasar II. Bandung: Bandung: Institut Teknologi Bandung.

Astuti, I. A. D. (2016). Pengembangan alat eksperimen cepat rambat bunyi dalam medium udara dengan menggunakan metode Time of Flight (ToF) dan Berbantuan Software Audacity. Unnes Physics Education Journal, 5(3), 18-24.

Boimau, I., Irmawanto, R., \& Taneo, M. F. (2019). Rancang bangun alat ukur laju bunyi di udara menggunakan sensor ultrasonik berbasis arduino. Cyclotron, 2(2), 1-7.

Firdiani, Handhika, J., \& Kurniadi, E. (2019). Potensi kesenian tradisional dongkrek dalam pembelajaran fisika pada materi gelombang bunyi. In Prosiding Seminar Nasional Pendidikan Fisika V, 1-12.

Giancoli, D. C. (2015). Physics Principles with Applications, Global Edition. England: Pearson Education Limited.

Hartanto, O., \& Haryanti, M. (2018). Sistem pemantau rumah jarak jauh dengan komunikasi wireless. Jurnal Teknologi Industri, 7, 32-39.

Ikhwan, N., \& Pramudya, Y. (2018). Cepat rambat bunyi di udara pada variasi suhu dengan memanfaatkan sensor suara berbantuan Logger pro dan Audacity. Wahana Fisika, 3(1), 11-18.

Lubis, A. M., \& Lizalidiawati. (2005). Rancang-bangun alat penentuan kecepatan bunyi di udara berbasis instrumentasi. GRADIEN: Jurnal Ilmiah MIPA, 1(1), 10-15.

Monpezat, A., Topin, S., Deliere, L., Farrusseng, D., \& Coasne, B. (2019). Evaluation methods of adsorbents for air purification and gas separation at low concentration: Case studies on xenon and krypton. Industrial \& Engineering Chemistry Research, 58(11), 4560-4571.

Muhafid, E. A., \& Primadi, M. R. (2014). Pengembangan alat eksperimen bunyi dengan sistem akuisisi data berbasis smartphone android. Jurnal Fisika, 4(2), 83-87.

Nasution, A., Wahab, A., \& Nuari, D. (2018). Analisis pengaruh benang wol dan limbah batang pisang dalam rancangan produk komposit peredam bunyi ruang akustik. Jurnal Sistem Teknik Industri, 20(2), 53-62.

Nurkholis, Junaidi, \& Surtono, A. (2014). Rancang bangun sistem akuisisi data resonansi gelombang bunyi menggunakan transduser ultrasonik berbasis mikrokontroler ATmega8535. Jurnal Teori dan Aplikasi Fisika, 2(2), 165-169.

Ulinuha, A. H. (2018). Bunyi dalam prespektif al qur'an dan sains. PROSIDING Seminar Nasional Pendidikan Fisika FITK UNSIQ, 1(1), 112-114.

Walker, J., Halliday, D., \& Resnick, R. (2014). Fundamentals of physics (10th editi). United State: Wiley.

Yebra, F., Troncoso, J., \& Romaní, L. (2017). Fully automatized apparatus for determining speed of sound for liquids in the temperature and pressure interval (283.15-343.15) $\mathrm{K}$ and (0.1-95) MPa. The Journal of Chemical Thermodynamics, 104, 102-109. 